\title{
Editorial
}

\section{Foreword to this special issue on the Society \& Materials seminars}

The Society \& Materials seminars, SAM, have been meeting regularly since 2007, in Seville, Spain, in Nantes, France, in Freiberg, Germany, in Nancy, France, in Metz, France and in Leuven, Belgium. SAM-7 will take place in Aix-la-Chapelle, Germany, in April 2013. SAM seminars have been organized by ArcelorMittal and by the host of the event, a university or a research institute.

The meetings attract 30 to 40 communications, presented in plenary or in poster sessions. Papers are posted on-line on the SOVAMAT website, www.sovamat.org. The attendance is of the order of 100 people, who come from all over the world, Europe, Far East and America.

Revue de Métallurgie has expressed interest in publishing a selection of peer-reviewed papers from the SAM seminars and this special issue is the third occasion, when this happens. Papers are mostly from SAM-6, held in Leuven, 2012.

The seminars stem from the SOVAMAT Initiative, a scientific agenda drawn by industry and academia to propose a transversal, pluridisciplinary, multi-material approach to analyze and describe the role of materials, especially structural materials, in society. Materials are present in all artifacts which support human endeavors and the history of mankind can be told as the parallel history of ideas and of materials. The connection is very deep, as materials constitute the backbone of the anthroposphere and provide the frontiers that protect people and their tools from the aggression of the biosphere, which follows different rules from society's and engineering sciences. The coexistence of both realms is actually ensured to a large extent by materials.

This broad and sometimes fuzzy connection covers issues which are traditionally in the area of both hard and subtitle sciences: thus material scientists, economists, natural and industrial ecologists and sociologists populate SAM meetings, a rare mixture of disciplines in an international conference. This transdisciplinarity is also tackled directly by the pluridisciplinary field of Sustainability and has a number of tools at its disposal, like Life Cycle Assessment (LCA), Material Flow Analysis (MFA), Technology Assessment (TA), etc.

The SAM seminars have the ambition to explore these complex connections between mankind and materials and to develop the proper metrics to describe them. LCA has an important role to play in this agenda, provided it evolves and addresses the challenge of accepting more complexity, while at the same time simplifying its methodology. But much is also expected from the soft science disciplines and from other tools like MFA.

Eventually, a new metrics might emerge, which is the grail of the SOVAMAT initiative.

The present issue publishes 10 papers, which picture how far the SAM community has journeyed along the lines of this agenda. 